Jurnal Teknik Komputer AMIK BSI

Volume 7, No.2, Juli 2021

P-ISSN 2442-2436, E-ISSN: 2550-0120

Akreditasi Ristekdikti, No: 36/E/KPT/2019 (Sinta 4)

DOI: $10.31294 /$ jtk.v4i2

\title{
Pengujian Tingkat Reliabilitas Metode Weight Aggregated Sum Product Assessment Menggunakan Pearson Correlation
}

\author{
Hidayanti Murtina ${ }^{1}$, Nunung Hidayatun², Susafaati $^{3}$ \\ ${ }^{1,3}$ Sekolah Tinggi Management Informatika dan Komputer Nusa Mandiri /Teknik Informatika \\ e-mail: hidayanti.hym@nusamandiri.ac.id \\ e-main: susafaati.suf@nusamandiri.ac.id \\ ${ }^{2}$ Universitas Bina Sarana Informatika/Sistem Informasi \\ e-mail: nunung.ntn@bsi.ac.id
}

\begin{tabular}{ccc} 
Diterima & Direvisi & Disetujui \\
$29-03-2021$ & $14-06-2021$ & $28-06-2021$ \\
\hline
\end{tabular}

\begin{abstract}
Abstrak - Kegiatan penilaian terhadap guru merupakan kegiatan yang umum di lakukan. Penilian guru teladan merupakan salah satu kegiatan yang diadakan setiap tahun di sekolah khususnya di SMP PGRI Babelan. Pemilihan guru teladan yang dilakukan oleh SMP PGRI Babelan haruslah seminimal mungkin terbebas dari halhal yang dapat merusak hasil seperti melakukan penilaian secara subjectif untuk itu penulis melakukan penelitian dengan menggunakan salah satu metode multi attribute decision making yaitu metode WASPAS. Kriteria yang digunakan dalam pemilihan guru teladan di SMP PGRI Babelan antara lain Etika, Metodik dan Didaktik, Tanggung Jawab, Kredibilitas, KetidakHadiran dengan tahapan dari metode WASPAS sendiri terdiri dari tahapan normalisasi matriks, pencarian nilai $\mathrm{Q}_{\mathrm{i}}^{\left({ }^{(1)}\right.}$ yaitu nilai Weighted Sum Model (WSM), pencarian nilai $\mathrm{Q}_{\mathrm{i}}^{(2)}$ yaitu nilai Weighted Product Model (WPM) dan tahapan metode WASPAS itu sendiri sehingga didapat bahwa alternatif ke-6 merupakan guru yang paling direkomendasikan oleh metode WASPAS dengan nilai 0.9860 disusul dengan alternatif ke-1 dengan perolehan nilai 0.8907 dan diujikan kembali tingkat reliabilitasnya dengan menggunakan Pearson Correlation.
\end{abstract}

Kata Kunci: Pearson Correlation, Reliabilitas, WASPAS

\begin{abstract}
Teacher assessment activities are common activities carried out. Evaluation of exemplary teachers is one of the activities held every year in schools, especially at PGRI Babelan Junior High School. The selection of exemplary teachers carried out by SMP PGRI Babelan must be as minimum as possible free from things that can damage the results such as conducting a subjective assessment, therefore the author conducted research using one of the multi attribute decision making methods, namely the WASPAS method. . The criteria used in the selection of exemplary teachers at SMP PGRI Babelan include Ethics, Methods and Didactics, Responsibility, Credibility, Absence with the stages of the WASPAS method itself consisting of matrix normalization stages, searching for the value of Qi (1) namely the value of the Weighted Sum Model (WSM), the search for the value of Qi (2), namely the value of the Weighted Product Model (WPM) and the stages of the WASPAS method itself so that it is found that the 6th alternative is the teacher most recommended by the method. WASPAS with a value of 0.9860 followed by the 1st alternative with a value of 0.8907 and re-tested the level of reliability using Pearson Correlation.
\end{abstract}

Keywords: Pearson Correlation, Reliability, WASPAS

\section{PENDAHULUAN}

Kegiatan penilaian terhadap guru merupakan kegiatan yang umum di lakukan, salah satunya diadakan setiap tahun di SMP PGRI Babelan. Guru merupakan pendidik profesional dan berperan aktif dalam mencerdaskan anak- anak bangsa. Yang kita ketahui guru juga merupakan langkah awal kita bisa mengerti membaca, menulis, menghitung dan sebagainya.
Peran guru sangatlah penting untuk mendidik dan mengajar, karena guru adalah seorang fasilitator, inspirator,motivator, imajinasi, kreativitas, empati sosial, dan tim kerja serta pengembang nilai-nilai karakter tidak dapat digantikan oleh teknologi. (LUBIS, 2020) oleh sebab itu Guru merupakan ujung tombak dalam menyampaikan informasi (pengetahuan) dalam dunia pendidikan.(Suhara et al., 2020) untuk itu diperlukan guru yang sosok guru teladan yang dapat dijadikan panutan. 
Kepuasan pengguna bisa dilihat dari kualitas sistem dan informasi yang saling berkesinambungan sehingga dapat memberikan manfaat. (Hasyim et al., 2019) dengan penggunaan teknologi informasi yang maksimal yang dibuat dalam bentuk sistem informasi maka segala sesuai pekerjaan yang berhubungan dengan data dapat dikerjakan dengan cepat, tepat dan akurat. Penyimpanannya pun dapat lebih terarah sehingga memudahkan dalam pengorganisasiannya. (Murtina, 2018)

Metode MOORA dinilai kurang memberikan hasil yang akurat dalam menganalisa keputusan bila dibandingkan dengan metode WASPAS. (Lukita et al., 2020). Penggunaa metode WASPAS dapat memaksimalkan pengambilan keputusan dengan melakukan perankingan. (Haryanti et al., 2019)

Salah satu sistem yang telah dibangun dengan metode WASPAS adalah rekomendasi pemilihan laptop, dimana metode ini menggabungkan antara WSM dan WPM. WASPAS sangat cocok untuk menyelesaikan permasalahan yang memiliki banyak kriteria (Multi Criteria Decision Making) (Chandra \& Hansun, 2019). It was estimated that accuracy applying WASPAS increases up to 1.3 times as compared to WPM and up to 1.6 times as compared to WSM. Consequently, it was ascertained that the proposed joint method enables to increase the ranking accuracy.. (Zavadskas et al., 2012)

Berdasarkan semua data yang ada maka pemilihan ataupun penetapan guru teladan yang dilakukan oleh SMP PGRI Babelan haruslah seminimal mungkin terbebas dari hal-hal yang dapat merusak hasil seperti melakukan penilaian secara subjectif sehingga guru yang ditetapkan sebagai guru teladan tidaklah dapat menjadi telaadan bagi rekan kerja guru lainnya maupun para siswa dan siswi di sekolah tersebut.

Untuk itu perlu dikombinasikan antara kemampuan stakeholder dalam mengambil keputusan dengan kemampuan teknologi dan sistem informasi dalam mengelola data yang ada menggunakan metode penunjang keputusan yaitu metode WASPAS dan melakukan pengujian kembali terhadap hasil dari metode tersebut dengan melakukan pengujian reliabilitas menggunakan Pearson Correlation untuk mendapatkan hasil semaksimal dan seakurat mungkin.

\section{METODOLOGI PENELITIAN}

Metodelogi penulis yang peneliti gunakan sebagai berikut:

\section{Pengumpulan data}

Penulis melakukan pengumpulan data dengan cara: a. Observasi

Penulis melakukan observasi terhadap setiap tahapan dalam menentukan siapakah yang akan ditetapkan sebagai guru teladan di SMP PGRI Babelan. Dengan mengumpulkan kriteria apa saja yang dibutuhkan, cara penilaian sampai dengan proses pengambilan keputusannya.

b. Wawancara

Penulis melakukan wawancara dengan pihakpihak yang terlibat dalam mengambil keputusan.

\section{c. Studi Pustaka}

Selain itu penulis juga melakukan tinjauan kasus dengan mempelajari jurnal-jurnal yang terkait dengan penelitian yang penulis lakukan terutama dengan penerapan metode WASPAS dan Pearson Correlation.

\section{Teknik Pengambilan Keputusan}

Didalam penelitian ini penulis menggunakan metode WASPAS sebagai metode untuk membantu stakeholder dalam menetapkan siapakah guru yang benar-benar berhak mendapatkan gelar atau predikat sebagai guru teladan di SMP PGRI Babelan.

Penggunaan metode ini tentunya hanya sebatas sebagai alat bantu stakeholder sedangkan kebijakan yang akan diterapkan dengan menggunakan metode ini tentunya akan tetap menggunakan kebijakan sekolah didalam menentukan guru teladan. Sedangkan untuk mengujian tingkat reliabilitas terhadap hasil dari metode tersebut menggunakan Pearson Correlation.

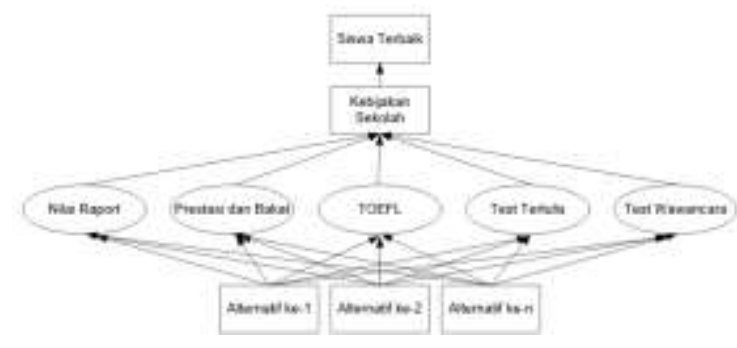

Sumber : (Murtina, 2020)

Gambar 1. Kerangka Pemikiram Penentuan Siswa Terbaik

Kerangka pemikiran yang digunakan pada penelitian ini menggunakan gambar 1.

Berdasarkan penerapan kerangka pemikiran tersebut dan digabungkan dengan kebijakan yang dilakukan sekolah dalam hal ini SMP PGRI Babelan maka akan didapat kerangka pemikiran pemilihan guru teladan seperti pada gambar 2 . 


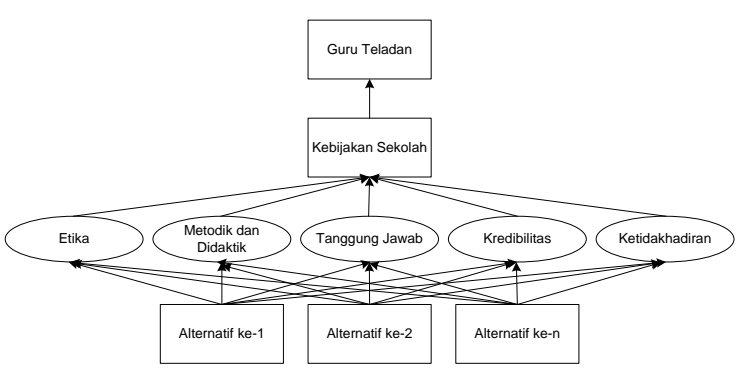

Sumber : Penelitian (2020)

\section{Gambar 2. Kerangka Pemilihan Guru Teladan}

Dari gambar 2 dapat dilihat dimana masing-masing alternatif dalam hal ini adalah guru yang akan menjadi kandidat sebagai guru teladan akan dilakukan penilaian terhadap lima kriteria antara lain etika, motodik dan didaktik, tanggung jawab, kredibilitas dan ketidakhadiran.

Setelah alternatif dan kriteria penilaian dilakukan tentunya tahapan selanjutnya adalah dengan menerapkan kebijakan sekolah didalam menentukan atau memilih guru teladan sehingga didapatkanlah guru teladan yang memang dapat menjadi panutan atau teladan baik bagi rekan kerja maupun masyarakat sekolah pada umumnya, sehingga harapan sekolah untuk memiliki seorang guru yang dapat menjadi role model di sekolah tersebut untuk menjadi lebih baik dapat tercapai.

Motode WASPAS sendiri melewati 4 langkah (Zavadskas et al., 2016) antara lain:

a. Tahapan Normalisasi

Normalisasi dilakukan dengan mengubah nilai dari kriteria masing-masing alternative dengan rumus 1 atau rumus 2 .

Apabila nilai tersebut bersifat keuntungan maka yang digunakan adalah rumus 1 .

$$
\bar{x}_{i j}=\frac{x_{i j}}{\max _{i j} x_{i j}}
$$

Keterangan:

$\bar{x}_{i j}=$ Nilai normalisasi .

$x \quad=$ Nilai kriteria awal.

$i \quad=$ Alternatif ke-i

$j \quad=$ Kriteria ke-j

Namun apabila nilai kriteria tersebut merugikan maka rumus yang digunakan adalah rumus 2 .

$\bar{x}_{i j}=\frac{\min _{i} x_{i j}}{x_{i j}}$

Kriteria dinilai menguntungkan jika nilainya memiliki nilai positif atau keuntungan bagi alternatif, semakin tinggi nilainya maka akan semakin bagus.

Sedangkan akan bernilai Cost apabila nilai dari kriteria tersebut memiliki nilai negatif atau merugikan bagi alternatif, semakin rendah nilainya maka akan semakin bagus.

b. Tahapan perhitungan WSM (Weighted Sum Model) dengan menggunakan rumus 3.

$$
W S M_{i}=\sum_{j=1}^{n} \bar{x}_{i j} \cdot w_{j}
$$

Keterangan :

$W_{S M}=$ Nilai dari Weighted Sum Model masingmasing alternatif

$\bar{x}_{i j}=$ Nilai yang dinormalisasi .

$w \quad=$ Bobot kriteria

$i \quad=$ Alternatif ke-i

$j \quad=$ Kriteria ke- $\mathrm{j}$

c. Tahap perhitungan WPM (Weighted Product Model)dengan menggunakan rumus 4.

$$
W P M_{i}=\prod_{j=1}^{n}\left(\bar{x}_{i j}\right)^{w_{i}}
$$

Keterangan :

$W P M_{i}=$ Nilai dari Weighted Product Model masing-masing alternatif

$\bar{x}_{i j}=$ Nilai yang dinormalisasi

$w \quad=$ Bobot kriteria

$i=$ Alternatif ke-i

$j \quad=$ Kriteria ke- $\mathrm{j}$

d. Tahapan Perhitungan WASPAS (Weight Aggregated Sum Product) menggunakan rumus 5

$$
\mathrm{Q}_{\mathrm{i}}=0.5 \mathrm{Q}^{(1)}+0.5 \mathrm{Q}^{(2)}
$$

$$
\begin{aligned}
& \text { Keterangan: } \\
& \mathrm{Q}_{\mathrm{i}}=\text { Merupakan nilai total WASPAS } \\
& \mathrm{Q}_{\mathrm{i}^{(1)}}=\text { Merupakan nilai WSM } \\
& \mathrm{Q}_{\mathrm{i}}^{(2)}=\text { Merupakan nilai WPM }
\end{aligned}
$$

Kerangka pemilikiran yang digunakan dalam menunjang pemilihan guru terbaik di SMP PGRI Babelan menggunakan metode WASPAS akan terlihat seperti pada gambar 3 yaitu dengan melakukan penetapan alternative, lalu menentukan criteria yang digunakan dalam penentuan, setelah itu memberikan bobot terhadap criteria yang telah ditentukan baru melakukan proses perhitungan dengan metode WASPAS.

Setelah didapat hasil dari perhitungan WASPAS maka dilakukan perankingan terhadap hasil sehingga didapatkan alternative yang memiliki nilai tertinggi merupakan alternative yang paling disarankan untuk dipilih sebagai guru teladan atau terbaik. 


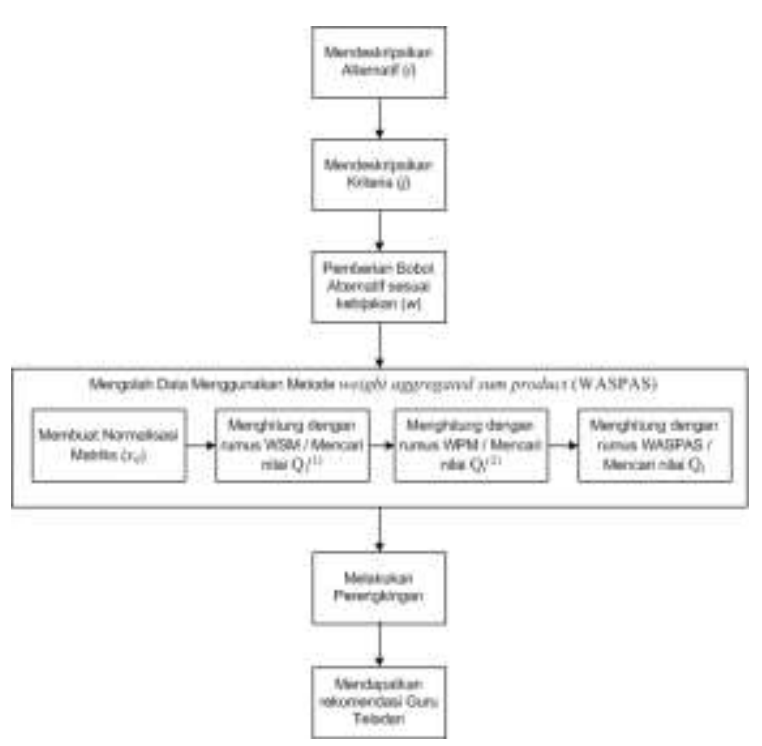

Sumber : Penelitian (2020)

Gambar 3. Kerangka Pemikiran Pemilihan Guru Teladan Menggunakan WASPAS

Setelah dilakukan proses pengelolahan menggunakan metode WASPAS maka selanjutnya dilakukan pengujian dengan menggunakan Pearson Correlation.

Tahapan pengujian Pearson Correlation, yaitu:

a. Melakukan pencarian nilai r sebagai nilai relasi.

$$
r_{n y}=\frac{n \sum X Y-\sum X \sum Y}{\sqrt{\left[n \sum X^{2}-(\Sigma X)^{2}\right]\left[n \Sigma Y^{2}-(\Sigma Y)^{2}\right.}}
$$

b. Melakukan pencarian nilai t sebagai pengujian hipotesa.

$$
t=\frac{r}{\sqrt{\frac{1-r^{2}}{n-2}}}
$$

\section{HASIL DAN PEMBAHASAN}

Berdasarkan dari pembahasan metodelogi penelitian yang dilakukan oleh penulis maka hasil yang didapat dari kerangka pemikiran yang dilakukan penulis yang pertama adalah menetapkan atau mendekripsikan siapa saja guru yang akan menjadi kandidat atau alternative dalam pemilihan guru teladan sehingga didapat data seperti pada tabel 1 .

Tabel 1. Tabel Alternatif

\begin{tabular}{cl}
\hline Alternatif & \multicolumn{1}{c}{ Nama Alternatif } \\
\hline Alt 1 & Herpinah, S.Pd \\
\hline Alt 2 & Elyanih, S.Pd \\
\hline Alt 3 & Neneng Hasanah, S.Pd \\
\hline Alt 4 & Anna Susana, S.Pd MM \\
\hline
\end{tabular}

\begin{tabular}{cl}
\hline Alt 5 & Ayu Aprianti, S.Pd \\
\hline Alt 6 & Dedeh Rusmiati, S.Ag \\
\hline Alt 7 & Dea Kartika Aulia Arawi \\
\hline Alt 8 & Dedi Sulaiman, S.Pd \\
\hline Alt 9 & Ayu Nurazizah, S.Pd \\
\hline Alt 10 & Respi Retna Ningtias, S.Pd \\
\hline Alt 11 & Wahyu Hidayat, S.Pd \\
\hline Alt 12 & Parulian Sihaloho \\
\hline Alt 13 & Rahmat Sobirin \\
\hline
\end{tabular}

Sumber : SMP PGRI Babelan (2020)

Berdasarkan tabel 1 dapat dilihat ada total 13 guru yang akan menjadi kandidat sebagai guru teladan di SMP PGRI Babelan yang akan dijadikan sebagai alternative $(i)$.

Setelah mendapatkan alternative (i) selanjutnya adalah menetapkan kriteria yang akan dijadikan sebagai acuan dalam menilai alternative yang ada sesuai dengan kebijakan sekolah dalam memilih guru teladan, sehingga akan didapat tabel 2.

Tabel 2. Tabel Kriteria

\begin{tabular}{cl}
\hline Kriteria & \multicolumn{1}{c}{ Nama Kriteria } \\
\hline Crt 1 & Etika \\
\hline Crt 2 & Metodik dan Didaktik \\
\hline Crt 3 & Tanggung Jawab \\
\hline Crt 4 & Kredibilitas \\
\hline Crt 5 & Ketidakhadiran \\
\hline
\end{tabular}

Sumber : SMP PGRI Babelan (2020)

Kriteria-kriteria yang didapat ini adalah kriteria yang akan digunakan dalam menggunakan metode WASPAS yang disebut kriteria $(j)$.

Setelah kriteria didapat maka diperlukan menentukan bobot $\operatorname{kriteria}(w)$ dan mengklasifikasikannya, sehingga didapat tabel 3 .

Tabel 3. Tabel Bobot dan Klasifikasi

\begin{tabular}{crl}
\hline Kriteria & \multicolumn{1}{c}{ Bobot } & Klasifikasi \\
\hline Crt 1 & 0.25 & Benefit \\
\hline Crt 2 & 0.25 & Benefit \\
\hline Crt 3 & 0.2 & Benefit \\
\hline Crt 4 & 0.2 & Benefit \\
\hline Crt 5 & 0.1 & Cost
\end{tabular}

Sumber : SMP PGRI Babelan (2020)

Bobot dan pengklasikasian yang digunakan sesuai dengan kepentingan dari masing-masing kriteria dalam pemilihan guru teladan dengan total bobot yang penulis gunakan mencapai angka 1 yang disesuaikan dengan kebijakan stakeholder, sedangkan kriteria penulis klasifikasikan berdasarkan nilai dari kriteria itu sendiri apakah menjadi sebuah keuntungan (benefit) ataukan sebuah beban (cost) dalam memilih guru teladan dan membuatnya menjadi matriks berpasangan. 
Tabel 4. Tabel Berpasangan

\begin{tabular}{cccccc}
\hline & \multicolumn{5}{c}{ Kriteria } \\
\cline { 2 - 6 } Alternatif & Crt & Crt & Crt & Crt & Crt \\
& 1 & 2 & 3 & 4 & 5 \\
\hline Alt 1 & 80 & 85 & 90 & 90 & 2 \\
\hline Alt 2 & 80 & 90 & 70 & 85 & 4 \\
\hline Alt 3 & 80 & 70 & 80 & 75 & 2 \\
\hline Alt 4 & 90 & 90 & 80 & 75 & 3 \\
\hline Alt 5 & 70 & 75 & 69 & 75 & 6 \\
\hline Alt 6 & 90 & 85 & 90 & 95 & 1 \\
\hline Alt 7 & 80 & 70 & 90 & 65 & 7 \\
\hline Alt 8 & 85 & 70 & 80 & 80 & 5 \\
\hline Alt 9 & 90 & 80 & 70 & 85 & 3 \\
\hline Alt 10 & 70 & 65 & 80 & 85 & 2 \\
\hline Alt 11 & 80 & 85 & 90 & 90 & 8 \\
\hline Alt 12 & 85 & 75 & 80 & 80 & 3 \\
\hline Alt 13 & 40 & 70 & 50 & 75 & 1 \\
\hline
\end{tabular}

Sumber : SMP PGRI Babelan (2020)

Setelah semua data yang dibutuhkan penulis dapat maka tahapan metode weight aggregated sum product (WASPAS) sudah dapat dilakukan. Tahapan yang pertama adalah melakukan normalisasi matriks sehingga didapat tabel 5 .

Tabel 5. Hasil Normalisasi Matriks

\begin{tabular}{cccccc}
\hline \multirow{2}{*}{ Alternatif } & \multicolumn{5}{c}{ Kriteria } \\
\cline { 2 - 6 } C1 & C2 & C3 & C4 & C5 \\
\hline Alt 1 & 0.8889 & 0.9444 & 1.0000 & 0.9474 & 0.5000 \\
\hline Alt 2 & 0.8889 & 1.0000 & 0.7778 & 0.8947 & 0.2500 \\
\hline Alt 3 & 0.8889 & 0.7778 & 0.8889 & 0.7895 & 0.5000 \\
\hline Alt 4 & 1.0000 & 1.0000 & 0.8889 & 0.7895 & 0.3333 \\
\hline Alt 5 & 0.7778 & 0.8333 & 0.7667 & 0.7895 & 0.1667 \\
\hline Alt 6 & 1.0000 & 0.9444 & 1.0000 & 1.0000 & 1.0000 \\
\hline Alt 7 & 0.8889 & 0.7778 & 1.0000 & 0.6842 & 0.1429 \\
\hline Alt 8 & 0.9444 & 0.7778 & 0.8889 & 0.8421 & 0.2000 \\
\hline Alt 9 & 1.0000 & 0.8889 & 0.7778 & 0.8947 & 0.3333 \\
\hline Alt 10 & 0.7778 & 0.7222 & 0.8889 & 0.8947 & 0.5000 \\
\hline Alt 11 & 0.8889 & 0.9444 & 1.0000 & 0.9474 & 0.1250 \\
\hline Alt 12 & 0.9444 & 0.8333 & 0.8889 & 0.8421 & 0.3333 \\
\hline Alt 13 & 0.4444 & 0.7778 & 0.5556 & 0.7895 & 1.0000 \\
\hline Sum : Hasl Penlitian $(2021)$ & & &
\end{tabular}

Sumber : Hasil Penelitian (2021)

Tabel 5 merupakan tabel hasil normalisasi matriks dengan melakukan perhitungan terhadap tabel 4 dengan menggunakan rumus 1 dan 2 sesuai dengan klasifikasi kriteria yang sudah ditetapkan sebelumnya.

Selanjutnya dilakukan pencarian nilai Weigted Sum Model (WSM $\left.\mathrm{W}_{\mathrm{i}} / \mathrm{Q}_{\mathrm{i}}^{(1)}\right)$ terhadap tabel normalisasi matriks sehingga didapat tabel 5.

Tabel 6. Hasil Perhitungan Weigted Sum Product (WSM)

\begin{tabular}{cc}
\hline Alternatif & $\mathbf{Q}_{\mathbf{i}}{ }^{\mathbf{( 1 )}}$ \\
\hline Alt 1 & 0.8978 \\
\hline Alt 2 & 0.8317 \\
\hline Alt 3 & 0.8023 \\
\hline Alt 4 & 0.8690 \\
\hline
\end{tabular}

\begin{tabular}{cc}
\hline Alt 5 & 0.7307 \\
\hline Alt 6 & 0.9861 \\
\hline Alt 7 & 0.7678 \\
\hline Alt 8 & 0.7968 \\
\hline Alt 9 & 0.8401 \\
\hline Alt 10 & 0.7817 \\
\hline Alt 11 & 0.8603 \\
\hline Alt 12 & 0.8240 \\
\hline Alt 13 & 0.6746
\end{tabular}

Sumber : Hasil Penelitian (2021)

Tabel 6 didapat dari melakukan perhitungan terhadap tabel 5 dengan menggunakan rumus 5 yaitu rumus pencarian WSM $\left(\mathrm{Q}^{(1)}\right)$.

Setelah nilai dari WSM $\left(\mathrm{Q}_{\mathrm{i}}{ }^{(1)}\right)$ maka dilakukan juga pencarian terhadap nilai dari Weighted Pruduct Model (WPM/ $\mathrm{Q}^{(2)}$ ) sehingga didapat tabel 7.

Tabel 7. Hasil Perhitungan Weighed Product Model (WPM)

\begin{tabular}{cc}
\hline Alternatif & $\left.\mathbf{Q}^{(\mathbf{2})}\right)$ \\
\hline Alt 1 & 0.8835 \\
\hline Alt 2 & 0.7862 \\
\hline Alt 3 & 0.7926 \\
\hline Alt 4 & 0.8347 \\
\hline Alt 5 & 0.6784 \\
\hline Alt 6 & 0.9858 \\
\hline Alt 7 & 0.6958 \\
\hline Alt 8 & 0.7438 \\
\hline Alt 9 & 0.8091 \\
\hline Alt 10 & 0.7716 \\
\hline Alt 11 & 0.7691 \\
\hline Alt 12 & 0.7964 \\
\hline Alt 13 & 0.6503 \\
\hline
\end{tabular}

Sumber : Hasil Penelitian (2021)

Tabel 7 didapat dengan melakukan perhitungan terhadap tabel 5 dengan menggunakan rumus 4 .

Tahapan terakhir sebelum melakukan perankingan adalah dengan melakukan pencarian nilai $\mathrm{Q}_{\mathrm{i}}$ dengan menggunakan rumus 5 .

Tabel 8. Hasil Perhitungan WASPAS

\begin{tabular}{cccc}
\hline Alternatif & $\mathbf{Q}_{\mathbf{i}}{ }^{(\mathbf{1})}$ & $\mathbf{Q}^{(\mathbf{2})}$ & $\mathbf{Q}_{\mathbf{i}}$ \\
\hline Alt 1 & 0.8978 & 0.8835 & 0.8907 \\
\hline Alt 2 & 0.8317 & 0.7862 & 0.8089 \\
\hline Alt 3 & 0.8023 & 0.7926 & 0.7975 \\
\hline Alt 4 & 0.8690 & 0.8347 & 0.8518 \\
\hline Alt 5 & 0.7307 & 0.6784 & 0.7045 \\
\hline Alt 6 & 0.9861 & 0.9858 & 0.9860 \\
\hline Alt 7 & 0.7678 & 0.6958 & 0.7318 \\
\hline Alt 8 & 0.7968 & 0.7438 & 0.7703 \\
\hline Alt 9 & 0.8401 & 0.8091 & 0.8246 \\
\hline Alt 10 & 0.7817 & 0.7716 & 0.7767 \\
\hline Alt 11 & 0.8603 & 0.7691 & 0.8147 \\
\hline
\end{tabular}




\begin{tabular}{cccc}
\hline Alt 12 & 0.8240 & 0.7964 & 0.8102 \\
\hline Alt 13 & 0.6746 & 0.6503 & 0.6624 \\
\hline
\end{tabular}

Sumber : Hasil Penelitian (2021)

Tabel 8 didapat dengan melakukan perhitungan terhadap tabel 6 dan tabel 7 dengan menggunakan rumus 5 .

Setelah nilai dari $\mathrm{Q}_{\mathrm{i}}$ didapat maka barulah dapat dilakukan perankingan terhadap hasil dari metode WASPAS sehingga akan didapat tabel perangkingan seperti yang tampak pada tabel 9 .

Tabel 9. Tabel Ranking

\begin{tabular}{crr}
\hline Alternatif & Qi & \multicolumn{2}{c}{ Ranking } \\
\hline Alt 1 & 0.9860 & 1 \\
\hline Alt 2 & 0.8907 & 2 \\
\hline Alt 3 & 0.8518 & 3 \\
\hline Alt 4 & 0.8246 & 4 \\
\hline Alt 5 & 0.8147 & 5 \\
\hline Alt 6 & 0.8102 & 6 \\
\hline Alt 7 & 0.8089 & 7 \\
\hline Alt 8 & 0.7975 & 8 \\
\hline Alt 9 & 0.7767 & 9 \\
\hline Alt 10 & 0.7703 & 10 \\
\hline Alt 11 & 0.7318 & 11 \\
\hline Alt 12 & 0.7045 & 12 \\
\hline Alt 13 & 0.6624 & 13 \\
\hline
\end{tabular}

Sumber : Hasil Penelitian (2021)

Dari tabel 9 dapat dilihat bahwa guru yang dijadikan sebagai alternative pertama sebagai guru teladan di SMP PGRI Babelan adalah alternative ke-6 disusul dengan alternative ke-1 yaitu dengan nilai masing-masing adalah 0.9860 dan 0.8907 .

\begin{tabular}{|c|c|c|c|}
\hline \multicolumn{4}{|c|}{ Correlations } \\
\hline & & VAR00001 & VAR00002 \\
\hline \multirow[t]{3}{*}{ VAR00001 } & Pearson Correlation & 1 & $.941^{\pi x}$ \\
\hline & Sig. (2-tailed) & & .000 \\
\hline & $N$ & 13 & 13 \\
\hline \multirow[t]{3}{*}{ VAR00002 } & Pearson Correlation & $.941^{\pi x}$ & 1 \\
\hline & Sig. (2-tailed) & .000 & \\
\hline & $N$ & 13 & 13 \\
\hline
\end{tabular}

Sumber : Hasil Penelitian (2021)

Gambar 4. Pengujian Pearson Correlation Menggunakan SPSS

Gambar 4 merupakan hasil pengujian reliabilitas dengan menggunakan Pearson Correlation menggunakan software SPSS.

\section{KESIMPULAN}

Kesimpulan dari penelitian ini adalah penggunaan sebuah metode tentunya akan mengurangi tingkat subjectivitas stakeholder dalam mengambil keputusan, penggunaan metode WASPAS dapat digunakan sebagai salah satu metode alternatif dalam pemilihan guru teladan di SMP PGRI Babelan. Metode WASPAS juga merupakan salah satu metode yang komputasi atau algoritmanya cukup sederhana sehingga mudah dimengerti, dari penelitian yang penulis lakukan dapat disimpulkan bahwa alternatif ke-6 merupakan guru yang paling direkomdasikan oleh metode ini disusul dengan alternatif ke-1, serta penggunaan metode WASPAS direkomendasikan oleh penilis karena memiliki nilai pengujian yang tinggi mencapai $0,941 *$ dengan hasil maximim pengujian adalah 1 dan yang terakhir adalah dibutuhkannya membangun sebuah GUI yang tentunya dapat lebih mempermudah pihak sekolah dalam menerapkan metode ini secara kontinyu.

\section{REFERENSI}

Chandra, K. A., \& Hansun, S. (2019). Sistem Rekomendasi Pemilihan Laptop Dengan Metode Waspas. Jurnal Ecotipe (Electronic, Control, Telecommunication, Information, and Power Engineering), 6(2), 76-81. https://doi.org/10.33019/ecotipe.v6i2.1019

Haryanti, T., Kurniawati, L., \& Riyadi, S. (2019). Sistem Pendukung Keputusan Penentuan Rumah Tangga Miskin Pada Desa Cibangkong Dengan Metode Waspas. Jurnal Riset Informatika, 1(4), 197-204. https://doi.org/10.34288/jri.v1i4.103

Hasyim, M. A. N., Cahyani, I. Y., \& Rosdiana, U. R. dan S. (2019). KEPUASAN DAN KUALITAS PENGGUNAAN SIAKADEMIK UNTUK MEMBERIKAN MANFAAT DALAM PEMBELAJARAN. 23(3), 2019. cholar.google.es/scholar?hl=es\&as_sdt=0\%2C $5 \& \mathrm{q}=$ Funcionalidad + Familiar+en + Alumnos $+\mathrm{d}$ $\mathrm{e}+1^{\circ}+\mathrm{y}+2^{\circ}+$ grado + de + secundaria + de + la + insti tución+educativa+parroquial+"Pequeña+Belén " + en + la + comunidad + de + Peralvillo $\% 2 \mathrm{C}+$ ubic ada+en+el+distrito+de+Chancay++ periodo+2018\&btnG $=$

LUBIS, M. (2020). Peran Guru Pada Era Pendidikan 4.0. EDUKA: Jurnal Pendidikan, Hukum, Dan Bisnis, 4(2), 0-5. https://doi.org/10.32493/eduka.v4i2.4264

Lukita, C., Nas, C., \& Ilham, W. (2020). Analisis Pengambilan Keputusan Penentuan Prioritas Utama Dalam Peningkatan Kualitas Mata Pelajaran Dengan Menggunakan Metode Perbandingan WASPAS dan MOORA. Jurnal Nasional Teknologi Dan Sistem Informasi, $5(3)$, 130-137. https://teknosi.fti.unand.ac.id/index.php/teknos i/article/view/1326/pdf

Murtina, H. (2018). Sistem Informasi Pengelolahan Data Persediaan Obat Menggunakan Metode Waterfall. 3(1), 1-10.

Murtina, H. (2020). Weight Aggregated Sum Product Assesment dalam Penentuan Siswa 
Terbaik. 4(2), 113-122.

Murtina, H., \& Mailasari, M. (2017). Pengukuran Tingkat Reliabilitas Metode Simple Additive Weighting Menggunakan Metode Pearson Correlation. INFORMATION SYSTEM FOR EDUCATORS AND PROFESSIONALS, 2(1), 21-30. http://ejournalbinainsani.ac.id/index.php/ISBI/article/view/6 11

Suhara, A. M., Firmansyah, D., \& Permana, I. (2020). Abdimas Siliwangi Abdimas Siliwangi. PELATIHAN PEMBELAJARAN ELEARNINGSOCRATIVEPADA GURU BAHASAINDONESIA KABUPATEN SUBANG, 03(01), 49-59.
Zavadskas, E. K., Kalibatas, D., \& Kalibatiene, D. (2016). A multi-attribute assessment using WASPAS for choosing an optimal indoor environment. Archives of Civil and Mechanical Engineering, 16(1), 76-85. https://doi.org/10.1016/j.acme.2015.10.002

Zavadskas, E. K., Turskis, Z., Antucheviciene, J., \& Zakarevicius, A. (2012). Optimization of weighted aggregated sum product assessment. Elektronika Ir Elektrotechnika, 122(6), 3-6. https://doi.org/10.5755/j01.eee.122.6.1810 